\title{
Object-Spatial Imagery: A New Self-Report Imagery Questionnaire
}

\author{
OLESSIA BLAJENKOVA, MARIA KOZHEVNIKOV* \\ and MICHAEL A. MOTES
}

Department of Psychology, Rutgers University, Newark, USA

\begin{abstract}
SUMMARY
A new instrument, the Object-Spatial Imagery Questionnaire (OSIQ), was designed to assess individual differences in visual imagery preferences and experiences. The OSIQ consists of two scales: an object imagery scale that assesses preferences for representing and processing colourful, pictorial, and high-resolution images of individual objects and a spatial imagery scale that assesses preferences for representing and processing schematic images, spatial relations amongst objects, and spatial transformations. Across a series of studies, the object imagery scale was significantly correlated with the performance on object imagery tasks; the spatial imagery scale was significantly correlated with the performance on spatial imagery tasks; but neither correlated with measures of intelligence. Additionally, compared to visual artists and humanities professionals, scientists reported higher spatial imagery ratings; however, compared to scientists and humanities professionals, visual artists reported higher object imagery ratings. Thus, the results from the studies supported the predictive, discriminant, and ecological validity of the OSIQ. Copyright (C) 2006 John Wiley \& Sons, Ltd.
\end{abstract}

Until recently, most of the investigations of individual differences in mental imagery, as well as the investigations of individual preferences for processing visual versus verbal information, have been based on the assumption that imagery is an undifferentiated, unitary construct and therefore that individuals may be simply classified as good or bad imagers (e.g. Hollenberg, 1970; Paivio, 1983; Richardson, 1977). However, considerable cognitive and neuroscience research (Farah, Hammond, Levine, \& Calvanio, 1988; Kosslyn, 1994; Kosslyn \& Koenig, 1992; Levine, Warach, \& Farah, 1985) challenges the view that mental imagery is unitary, and instead this research suggests the existence of two distinct object and spatial imagery subsystems that encode and process visual information in different ways. Object imagery refers to representations of the literal appearances of individual objects in terms of their precise form, size, shape, colour and brightness, whereas spatial imagery refers to relatively abstract representations of the spatial relations amongst objects, parts of objects, locations of objects in space, movements of objects and

*Correspondence to: Maria Kozhevnikov, Department of Psychology, Rutgers University, 333 Smith Hall, 101 Warren Street, Newark, NJ 07102, USA. E-mail: maria@psychology.rutgers.edu

Contract/grant sponsor: National Science Foundation; contract/grant numbers: REC0106760, REC135918. 
object parts and other complex spatial transformations (Hueur, Fischman, \& Reisberg, 1986; Kozhevnikov, Kosslyn, \& Shepard, in press; Reisberg, Culver, Hueur, \& Fischman, 1986). Furthermore, research has shown that these two imagery subsystems are anatomically and neurologically distinct (e.g. Farah et al., 1988; Kosslyn, Ganis, \& Thompson, 2001; Levine et al., 1985; Milner \& Goodale, 1995; Uhl, Goldenberg, Lang, \& Lindinger, 1990). For example, Levine et al. (also see Farah et al., 1988) demonstrated that lesions in temporal cortex disrupted performance on tasks that relied on visual images of objects and their properties, whereas such lesions did not disrupt performance on tasks that required spatial imagery. Lesions in posterior parietal cortex, however, had the reverse effect.

Dissociation between object and spatial imagery also has been found in research on individual differences in imagery (Hegarty \& Kozhevnikov, 1999; Kozhevnikov \& Kosslyn, 2000; Kozhevnikov, Hegarty, \& Mayer, 2002; Kozhevnikov et al., 2005). Kozhevnikov et al. (2005), for example, reported that verbalizers (i.e. those who prefer to use verbal-analytical coding versus imagery) typically performed at an 'intermediate' level on imagery tasks, whereas visualizers (i.e. those who reported strong and consistent preferences for processing information visually) could be divided into a group that scored poorly on spatial imagery tasks (e.g. mental rotation task) but excelled on object imagery tasks (e.g. degraded pictures task) and a group that excelled on spatial imagery tasks but scored poorly on object imagery tasks. Thus, two types of imagers were identified: object imagers who tend to construct colourful, pictorial, and high-resolution images of individual objects, and spatial imagers who tend to use imagery to schematically represent spatial relations among objects and to perform complex spatial transformations. The results of Kozhevnikov et al. (2005) also found that object imagers encoded and processed images holistically, as a single perceptual unit, whereas spatial imagers generated and processed images analytically, part by part. Furthermore, Kozhevnikov et al. (2005) found that scientists and engineers tended to be spatial imagers and that visual artists tended to be object imagers.

The focus of the present work was to develop a valid and reliable self-report instrument for assessing object and spatial mental imagery preferences and experiences. As stated above, many of the previous self-report instruments for assessing individuals' preferences for processing information visually were based on the implicit or explicit assumption that visual imagery is a unitary construct, that is, that a given individual can be classified generally as being a good or bad imager. Many of these previous self-report questionnaires, such as Paivio's Individual Differences Questionnaire (IDQ; Paivio, 1971) and Richardson's Verbalizer-Visualizer Questionnaire (VVQ; Richardson, 1977), have focused on distinguishing between visualizers and verbalizers, where visualisers were thought to have high-imagery ability and verbalizers were thought to have low imagery ability (e.g. based on responses to items found on the IDQ and VVQ, like 'I often use mental pictures to solve problems,' participants often have been classified as visualizers or verbalizers based on median split procedures). However, factor analysis of the individual IDQ items identified not only imagery and verbal factors, but also a number of more specific factors (Paivio \& Harshman, 1983). Moreover, men tended to score higher than women on items that related to the use of imagery in problem solving and that related to imagining moving objects, whereas women tended to score higher than men on items that related to the use of imagery in remembering and generating mental images of previously perceived scenes. Similarly, Green and Shroeder's (1990) principal components analysis failed to show that the VVQ items formed a homogenous scale; likewise, Boswell and Pickett's (1991) principle components analysis did not produce a clear factor structure that 
was acceptable, in the authors' opinion, for a test purportedly measuring a unitary construct. Thus, these analyses of the constructs underlying the IDQ and VVQ scores suggest that the imagery items from these scales assess more than one imagery preference. Moreover, several studies also have demonstrated that, although the verbal subscale of the VVQ is related to verbal ability measures (e.g. Green \& Schroeder, 1990; Kirby, Moore, \& Schofield, 1988), the visual subscale is only weakly related to ratings of the vividness of mental imagery and not even moderately related to other visual-spatial aptitude measures (e.g. Alesandrini, 1981; Edwards \& Wilkins, 1981; Green \& Schroeder, 1990; Parrott, 1986). In order to avoid noted problems associated with self-report measures like the IDQ and the VVQ, the Mathematical Processing Instrument (MPI) was designed by mathematics education researchers to measure students' individual differences in imagery preferences (Suwarsono, 1982, as cited in Lean \& Clements, 1981; Presmeg, 1986a; 1986b). The MPI included a number of simple mathematics problems that could be solved by either visual or analytical methods. Depending on their preferences for solving problems, visually versus analytically, participants were placed on a continuum called the degree of visuality. Although the MPI has shown internal reliability (Cronbach's $\alpha=0.87$ ), its predictive validity has been questioned. No clear relationship between the degree of visuality and students' performance on either mathematical or spatial ability tests has been found. Moreover, students who preferred to process information by verballogical means tended to outperform more visually inclined students on both spatial ability and mathematical tasks (Lean \& Clements, 1981).

Finally, self-report instruments assessing individual differences in imagery vividness, such as the Vividness of Visual Imagery Questionnaire (VVIQ; Marks, 1973) where people rate the vividness of their subjectively experienced visual images, have failed to establish significant correlations with spatial imagery tests (see McKelvie, 1995). One possible explanation for these null results is that introspective, self-report questionnaires are 'quite unreliable and can provide only little more than a rough index of imagery' (Lohman, 1979, pp. 149-150). Several issues have been raised regarding the validity (e.g. the influence of social desirability) of introspective assessments of imagery (e.g. Richardson, 1980; but see McKelvie, 1995); however, introspective vividness assessments have been shown to correlate with various visual perception tasks (e.g. gestalt closure; Wallace 1990) and some visual memory tasks (e.g. RT for short-term recognition memory for picture details; see Marks, 1983), thereby providing some evidence of criterion validity for such questionnaires (see McKelvie, 1995; Poltrock \& Agnoli, 1986). Another possibility is that imagery is not a single, undifferentiated construct and that selfreport instruments like the VVIQ simply do not assess aspects of spatial imagery but instead assess aspects of object imagery (Heuer et al., 1986; Kozhevnikov et al., 2005; Reisberg et al., 1986). Dean and Morris (2003), for instance, found that ratings of vividness, ease of formation, ease of maintenance and ease of transformation of schematic 'spatial' stimuli similar to those used in standard mental rotation tests correlated with performance on the mental rotation tests but that VVIQ ratings did not. Unlike ratings of the vividness of schematic 'spatial' stimuli, ratings of the vividness of the VVIQ images (e.g. a friend or relative, a familiar store, a country scene recalled or constructed from long-term memories) did not predict performance on spatial imagery tests. Thus, imagery self-reports, per se, do not appear to be a problematic issue, but it appears that it is the correspondence between the type of imagery assessed by the self-report instrument and the type of imagery required for a particular imagery task that matters. 
In summary, the above review suggests that a crucial problem with previous assessments of individual differences in imagery preferences and experiences has been the assumption that imagery ability is a single undifferentiated skill. The current research challenges previous attempts to develop such self-report measures of mental imagery. Instead, we focused on the construction of a new self-report instrument for imagery assessment, the Object-Spatial Imagers Questionnaire (OSIQ), based on cognitive psychology and neuroscience approaches that have emphasized a key distinction in visual information processing, namely, that there is a distinction between processing object properties and processing spatial relations. In the present paper, we report a series of studies examining the reliability and validity of the OSIQ. McKelvie (1994) has proposed guidelines for assessing the reliability, content validity (i.e. plausibility and reasonableness), and criterion validity (i.e. association with other related factors) of introspective imagery questionnaires, and the OSIQ data reported below are discussed in terms of these criteria. In Study 1, the OSIQ was designed and its factor structure and internal reliability were examined. Although the research reviewed above suggests the plausibility of the development of an introspective assessment of object and spatial imagery skills, 1) no such measure currently exists, 2) finding introspective-based evidence for a distinction between object and spatial imagery abilities would provide further validation of theory and research supporting such a distinction, and 3) a single, brief questionnaire to assess individual differences in object and spatial imagery will be useful in further research (e.g. McKelvie's, 1995, meta-analysis included over 200 studies that used the VVIQ) and applied (e.g. vocational decision making) settings. In Studies 2 and 3, the criterion (predictive and discriminant) validity of the OSIQ were examined, and in Study 4, the OSIQ was further validated on a sample of members of different professions known to use predominantly either object or spatial imagery in their training and work (i.e. professional visual artists and scientists, respectively).

\section{STUDY 1}

The first goal of Study 1 was to design the OSIQ consisting of two separate scales: an object imagery scale, with self-report items designed to assess object imagery preferences and experiences, and a spatial imagery scale, with self-report items designed to assess spatial imagery preferences and experiences. The second goal was to examine the factor structure and internal reliability of the OSIQ and to select the final items for the OSIQ.

\section{Method}

\section{Participants}

Two hundred fourteen undergraduates, (106 females and 108 males), ranging from 17 to 44 years of age $(M=20.33)$, were recruited from the participant pool at Rutgers UniversityNewark and the New Jersey Institute of Technology. There were 150 participants who were enrolled in psychology courses and 64 participants who were enrolled in computer science courses. The data were collected from a relatively large sample of college students to satisfy sample size suggestions for principle components analyses (see Stevens, 1996).

\section{Design of items for the OSIQ object and spatial scales}

Sixty initial items were developed to assess object and spatial imagery. Some of the items were variations of statements from previously developed questionnaires for 
assessing the visualizer-verbalizer cognitive style (Richardson, 1977; Paivio \& Harshman, 1983), and others were developed based on previous research and theoretical frameworks concerning distinctions between object and spatial imagery (Farah et al., 1988; Kosslyn \& Koenig, 1992; Levine et al., 1985) and distinctions in performance between object versus spatial visualizers (e.g. Hegarty \& Kozhevnikov, 1999; Kozhevnikov et al., 2002; Kozhevnikov et al., 2005). For instance, object imagers prefer to construct colourful, high-resolution, picture-like images of individual objects and to encode and process images holistically, whereas spatial imagers prefer to construct schematic representations of objects and spatial relations among objects, generate and process images part by part, and are capable of performing complex spatial transformations.

Thus, some items addressed qualitative characteristics (e.g. vividness, colourfulness, or abstractness) of images (e.g. object imagery items like my mental pictures are very detailed precise representations of the real things and spatial imagery items like my images are more like schematic representations of things and events); some items addressed image maintenance and transformation processes (e.g. object imagery items like I can close my eyes and easily picture a scene that I have experienced and spatial imagery items like I can easily rotate three-dimensional geometric figures); some items addressed preferences for certain types of visual representations, such as pictorial versus schematic representations, (e.g. object imagery items like I enjoy pictures with bright colours and unusual shapes like the ones in modern art and spatial imagery items like I prefer schematic diagrams and sketches when reading a textbook); and some items addressed self-estimates of abilities in performing tasks requiring the use of object or spatial imagery (e.g. object imagery items like I have excellent visual memory; I can recount what people wore for a dinner, the way they sat and looked and spatial imagery items like I am good at playing spatial games involving constructing from blocks and papers).

First, a pilot study was conducted with 25 Harvard psychology undergraduates (12 object imagers and 13 spatial imagers) in which the undergraduates were interviewed about all 60 items from the OSIQ as well as about their everyday use of object and spatial imagery. ${ }^{1}$ Second, to provide some evidence of the content (face) validity of the OSIQ, three experts in the field of mental imagery reviewed the OSIQ object and spatial items with regard to their relevance to object and spatial imagery. The agreement among the judges was $97 \%$. As a result, after excluding all of the controversial items identified during the interview sessions in the pilot study and after excluding all of the items on which there was a disagreement among the judges, 44 items were used in the current study.

\section{Procedure}

The participants were tested in groups. The participants were asked to read all of the questionnaire items and rate each of them on a 5-point scale with $1=$ totally disagree and $5=$ totally agree, and ratings " 2 " through " 4 " to indicate intermediate degrees of agreement/disagreement. The object and spatial items on the questionnaire were intermixed. No time limit was specified for the completion of the questionnaire.

\footnotetext{
${ }^{1}$ The pilot study was a part of a larger study reported in Study 2 in Kozhevnikov et al. (2002). Fifty-one psychology undergraduates from Harvard University were administered a set of object and spatial imagery tests. Based on their performance on these tests, 12 object imagers and 13 spatial imagers were identified, and they were further administered the OSIQ items in an interview session.
} 


\section{Results and discussion}

Principal components analysis was performed on the responses to the 44 items. Six items were negatively formulated (4 object items and 2 spatial items) and thus were reverse scored (e.g. totally agree $=1$ ). The initial analysis revealed 13 factors with eigenvalues above one. Two factors, however, had markedly higher eigenvalues (6.87 and 5.00) than the others (ranging from 2.09 to 1.05), and these first two factors explained $26.98 \%$ of the variance. Together, the other 11 factors explained an additional $35.12 \%$ of the variance. All of the items designed to assess object imagery experiences were positively loaded on the first factor, whereas all of the items designed to assess spatial imagery preferences either did not load or loaded negatively on this factor. Additionally, all of the items designed to assess spatial imagery preferences loaded positively on the second factor, whereas none of the items designed to assess object imagery preferences loaded on this factor. Thus, the first factor appeared to capture object imagery preferences, and the second factor appeared to capture spatial imagery preferences.

None of the other 11 factors met recommendations regarding component saturation (see Guadagnoli \& Velicer, 1988; e.g., four or more loadings above \pm 0.60 ). For example, none of the 11 factors had loadings above 0.60 (the loadings ranged from -0.499 to 0.467 ), only one of factor had three loadings with absolute values above 0.40 , four only had two loadings with absolute values above 0.40 , four only had one loading with an absolute value above 0.40 , and two did not have any loadings with absolute values above 0.40 . Thus, these factors were not considered further.

Based on the first results from the initial principal components analysis, a second principal components analysis with Varimax rotation was performed, and for this analysis, the factor structure was limited to two factors. This second analysis also yielded a predominantly object imagery factor and predominantly spatial imagery factor. From these two factors, object imagery items having low loadings on the predominantly object factor, spatial items having low loadings on the predominantly spatial factor, and items for which loadings on both scales were both positive or were both negative (i.e. those that were not discriminating between spatial and object imagery constructs) were excluded from further analysis. Fifteen items from the object imagery factor and 15 items from the spatial imagery factor (one of which was reverse coded) were retained. The final 30 OSIQ items and their loadings on the object and spatial imagery factors are presented in Table 1. In this table, the underlined loadings within the Object Factor 1 column identify items that were designed to measure object imagery, and underlined loadings within the Spatial Factor 2 column identify items that were designed to measure spatial imagery.

\section{Internal reliability of the object and spatial scales}

For each participant, the 15 items from each factor were averaged to create object and spatial scale scores. The resulting object scale descriptive statistics were $M=3.59$, $S D=0.57$, Minimum $=2.00$, and Maximum $=5.00$; and the resulting spatial scale descriptive statistics were $M=2.93, S D=0.60$, Minimum $=1.27$, and Maximum $=4.40$. For the object scale, Cronbach's $\alpha=0.83$, and for the spatial scale, Cronbach's $\alpha=0.79$, both of which are below McKelvie's (1994) recommended minimum acceptable coefficient of 0.85 but above other recommended minimum coefficients (ranging from 0.60 to 0.85 ) reviewed by McKelvie. Additionally, the two scales were negatively correlated $(r=-0.155, p=0.023$ ), and this correlation was consistent with previously 
Table 1. Principal component loadings, after Varimax rotation, for the OSIQ items

\begin{tabular}{|c|c|c|c|}
\hline & OSIQ Items* & $\begin{array}{l}\text { Object } \\
\text { Factor } 1\end{array}$ & $\begin{array}{c}\text { Spatial } \\
\text { Factor } 2\end{array}$ \\
\hline 1 & I was very good in 3-D geometry as a student. & 0.088 & 0.730 \\
\hline 2 & $\begin{array}{l}\text { If I were asked to choose between engineering professions and visual } \\
\text { arts, I would prefer engineering. }\end{array}$ & -0.255 & $\overline{0.522}$ \\
\hline 3 & Architecture interests me more than painting. & -0.117 & 0.592 \\
\hline 4 & My images are very colourful and bright. & 0.532 & $-\overline{0.009}$ \\
\hline 5 & $\begin{array}{l}\text { I prefer schematic diagrams and sketches when reading a textbook } \\
\text { instead of colourful and pictorial illustrations. }\end{array}$ & $-\overline{0.238}$ & 0.493 \\
\hline 6 & $\begin{array}{l}\text { My images are more like schematic representations of things } \\
\text { and events rather than detailed pictures. }\end{array}$ & -0.346 & $\underline{0.399}$ \\
\hline 7 & $\begin{array}{l}\text { When reading fiction, I usually form a clear and detailed mental } \\
\text { picture of a scene or room that has been described. }\end{array}$ & $\underline{0.497}$ & 0.019 \\
\hline 8 & I have a photographic memory. & 0.462 & 0.150 \\
\hline 9 & I can easily imagine and mentally rotate 3 -dimensional geometric figures. & $\overline{0.180}$ & 0.772 \\
\hline 10 & $\begin{array}{l}\text { When entering a familiar store to get a specific item, I can easily picture } \\
\text { the exact location of the target item, the shelf it stands on, } \\
\text { how it is arranged and the surrounding articles. }\end{array}$ & $\underline{0.553}$ & 0.01 \\
\hline 11 & $\begin{array}{l}\text { I normally do not experience many spontaneous vivid images; } \\
\text { I use my mental imagery mostly when attempting to solve some } \\
\text { problems like the ones in mathematics. }\end{array}$ & -0.365 & $\underline{0.138}$ \\
\hline 12 & My images are very vivid and photographic. & 0.756 & 0.029 \\
\hline 13 & I can easily sketch a blueprint for a building that I am familiar with. & $\overline{0.295}$ & 0.471 \\
\hline 14 & I am a good Tetris player. & 0.082 & $\overline{0.238}$ \\
\hline 15 & $\begin{array}{l}\text { If I were asked to choose between studying architecture and visual arts, } \\
\text { I would choose visual arts. }\end{array}$ & $\underline{0.434}$ & $-\overline{0.445}$ \\
\hline 16 & $\begin{array}{l}\text { My mental images of different objects very much resemble the size, } \\
\text { shape and colour of actual objects that I have seen. }\end{array}$ & $\underline{0.502}$ & 0.016 \\
\hline 17 & $\begin{array}{l}\text { When I imagine the face of a friend, I have a perfectly clear } \\
\text { and bright image. }\end{array}$ & $\underline{0.487}$ & -0.082 \\
\hline 18 & I have excellent abilities in technical graphics. & 0.119 & 0.666 \\
\hline 19 & $\begin{array}{l}\text { I can easily remember a great deal of visual details that someone else } \\
\text { might never notice. For example, I would just automatically take some } \\
\text { things in, like what colour is a shirt someone wears or } \\
\text { what colour are his/her shoes. }\end{array}$ & $\underline{0.592}$ & $-\overline{0.09}$ \\
\hline 20 & In high school, I had less difficulty with geometry than with art. & -0.099 & $\underline{0.360}$ \\
\hline 21 & $\begin{array}{l}\text { I enjoy pictures with bright colours and unusual shapes like the ones } \\
\text { in modern art. }\end{array}$ & 0.368 & $\overline{0.145}$ \\
\hline 22 & $\begin{array}{l}\text { Sometimes my images are so vivid and persistent that it is difficult } \\
\text { to ignore them. }\end{array}$ & $\underline{0.536}$ & 0.115 \\
\hline 23 & $\begin{array}{l}\text { When thinking about an abstract concept (e.g. 'a building') I imagine } \\
\text { an abstract schematic building in my mind or its blueprint rather } \\
\text { than a specific concrete building. }\end{array}$ & -0.029 & $\underline{0.424}$ \\
\hline 24 & My images are more schematic than colourful and pictorial. & -0.334 & 0.396 \\
\hline 25 & I can close my eyes and easily picture a scene that I have experienced. & 0.684 & $\overline{0.00}$ \\
\hline 26 & $\begin{array}{l}\text { I remember everything visually. I can recount what people wore } \\
\text { to a dinner and I can talk about the way they sat and the way they } \\
\text { looked probably in more detail than I could discuss what they said. }\end{array}$ & $\overline{0.594}$ & 0.028 \\
\hline 27 & $\begin{array}{l}\text { I find it difficult to imagine how a 3-dimensional geometric figure } \\
\text { would exactly look like when rotated. }\end{array}$ & 0.043 & $\underline{0.4}$ \\
\hline 28 & My visual images are in my head all the time. They are just right there. & 0.573 & 0.188 \\
\hline 29 & $\begin{array}{l}\text { My graphic abilities would make a career in architecture relatively } \\
\text { easy for me. }\end{array}$ & $\overline{0.061}$ & $\underline{0.70}$ \\
\hline 30 & $\begin{array}{l}\text { When I hear a radio announcer or a DJ I've never actually seen, } \\
\text { I usually find myself picturing what he or she might look like. }\end{array}$ & $\underline{0.480}$ & -0.206 \\
\hline
\end{tabular}

*The OSIQ questionnaire is copyright to Rutgers University, all rights reserved. No part of this questionnaire may be reproduced without prior written permission of Rutgers University. 
reported findings that many people prefer to use one type of imagery over the other (e.g. Kozhevnikov et al., 2002; Kozhenikov et al., 2005).

Additionally, to examine the test-retest reliability of the OSIQ, the new instrument was administered to another 24 undergraduates (20 females and four males, ranging from 19 to 37 years of age, $M=22.88$, enrolled in psychology courses at Rutgers University) on two occasions separated by one week. Object and spatial scores were computed by averaging across the 15 items for each subscale, and correlations between the testing sessions were computed. For the object scale, $r=0.813, p<0.001$, and for the spatial scale, $r=0.952$, $p<0.001$. These correlation coefficients, respectively, were within McKelvie's acceptable $(0.75 \leq r \leq 0.84)$ and very good $(r \geq 0.85)$ delayed test-retest reliability ranges.

In summary, the new OSIQ self-report instrument was developed based on the theoretical framework that postulates dissociation between object and spatial imagery. Principle components analysis of the items tested revealed that the items designed to address object and spatial imagery primarily loaded on two different factors. These results suggest that the two scales of the OSIQ assess the two distinct types of mental imagery, and this dissociation is consistent with previous cognitive and neuroscience research that has provided evidence for different object and spatial imagery subsystems (Levine et al., 1985; Farah et al., 1988; Kosslyn et al., 2001) and consistent with individual differences research that has provided evidence for two types, object and spatial, of imagers (Kozhevnikov \& Kosslyn, 2000; Kozhevnikov et al., 2002; Kozhevnikov et al., 2005).

Consistent with the individual differences research (e.g. Kozhevnikov et al., 2005), a negative correlation between the object and spatial scales was found. Those who gave high ratings on one scale tended to give lower ratings on the other scale. Furthermore, the two OSIQ scales demonstrated acceptable internal reliability, hence additionally supporting the value of separately assessing object and spatial mental imagery preferences and experiences.

\section{STUDIES 2a \& 2b}

The goals of Studies $2 \mathrm{a}$ and $2 \mathrm{~b}$ were to assess the criterion validity of the OSIQ. In order to evaluate the criterion validity of the OSIQ spatial and object imagery scales, the OSIQ scale scores were correlated with other measures of spatial and object imagery. For Study 2a, a large number of participants were administered the OSIQ and a battery of paper-and-pencil object and spatial imagery measures. For Study 2b, a smaller number of students were individually administered the OSIQ and a battery of computerized and paper-and-pencil object and spatial imagery measures.

\section{Method}

\section{Participants}

For Study 2a, one hundred forty six undergraduates ( 83 females and 63 males), ranging from 18 to 50 years of age, were recruited from the participant pool at Rutgers University-Newark. For Study 2b, forty-nine undergraduates (30 females and 19 males), ranging from 17 to 47 years of age, were recruited from the participant pool at Rutgers University-Newark.

\section{Procedure}

In Study 2a, participants were tested in groups of up to 25 during their recitations for an introductory psychology class. They were administered the OSIQ, a demographic 
questionnaire, two spatial imagery tests, and two object imagery tests. The spatial tests used were commonly used paper-and-pencil tests assessing spatial visualization skills: the Paper Folding test (Ekstrom, French, \& Harsman, 1976) and the Vandenberg-Kuse Mental Rotation test (Vandenberg \& Kuse, 1978). The object imagery tests used were the VVIQ (Marks, 1973) and the Degraded Pictures Test, which was a modification of the Degraded Pictures Test designed by Kozhevnikov et al. (in press).

In Study 2b, participants were tested individually and were administered the OSIQ, a demographic questionnaire, the Spatial Imagery Test from the Imagery Testing Battery (Version 1.0), and a computerized version of the Degraded Pictures Test from the Imagery Testing Battery (Version 1.0). Participants in Study $2 \mathrm{~b}$ were also administered the Paper Folding (Ekstrom et al., 1976) and Vandenberg-Kuse Mental Rotation (Vandenberg \& Kuse, 1978) tests. In Studies 2a and 2b, the tests were administered in a fixed random order.

\section{Materials}

Paper Folding Test. According to Ekstrom et al. (1976), the Paper Folding Test measures spatial visualization ability, which is the ability to apprehend, encode and mentally manipulate abstract spatial forms. The Paper Folding Test (Ekstrom et al., 1976) consisted of 10 items (for examples see Appendix). Each item consisted of successive drawings of two or three folds made to a square sheet of paper and a final drawing showing the folded paper with a hole punched through it. The participants were to select from among five drawings the one depicting how the paper would look when fully opened. They had $3 \mathrm{~min}$ to complete the test, and paper folding scores were calculated as the number of correct answers minus the quotient of the number of incorrect answers divided by four. The test-retest reliability is 0.84 (Ekstrom et al., 1976).

Vandenberg-Kuse Mental Rotation Test. The Vandenberg-Kuse Mental Rotation Test (Vandenberg \& Kuse, 1978) measures mental rotation transformation ability. The test consisted of 10 items (for examples see Appendix). For each item, participants compared 2-dimensional line drawings of 3-dimensional geometric figures composed of cubes. Each test-item consisted of a criterion figure and four comparison figures. Two of the comparison figures were rotated versions of the criterion figure, and the other two comparison figures were rotated mirror images of the criterion figure. Participants were to indicate which two of the four figures were rotated versions of the criterion figure, and they had 3 min to complete the test. Mental rotation scores were calculated as the number of items in which both rotated images of the criterion figure were correctly identified. For the Vandenberg-Kuse Mental Rotation Test, K-R $20=0.88$ (Wilson, DeFries, McClean, Vandenberg, Johnson, \& Rashad, 1975).

Spatial Imagery Test. The Spatial Imagery Test from the Imagery Testing Battery (Version 1.0) consisted of the three types of spatial imagery tasks: Wire Frame, Figure Rotation and Combination, and Folded Box problems. Each Wire Frame problem consisted of viewing a 2-dimensional rendering of a 3-dimensional transparent cube with a 'wire' (i.e. a thin black line) running along the surfaces of the cube (see Figure 1). The participants were to select from among six 2-dimensional line-drawings the drawing that depicted how the wire would look from a specified new perspective (e.g. from beneath). Each Figure Rotation and Combination problem consisted of viewing 2-dimensional renderings of two 3-dimensional figures composed of cubes placed on a grid (see Figure 2). The participants were to imagine combining the figures by rotating 

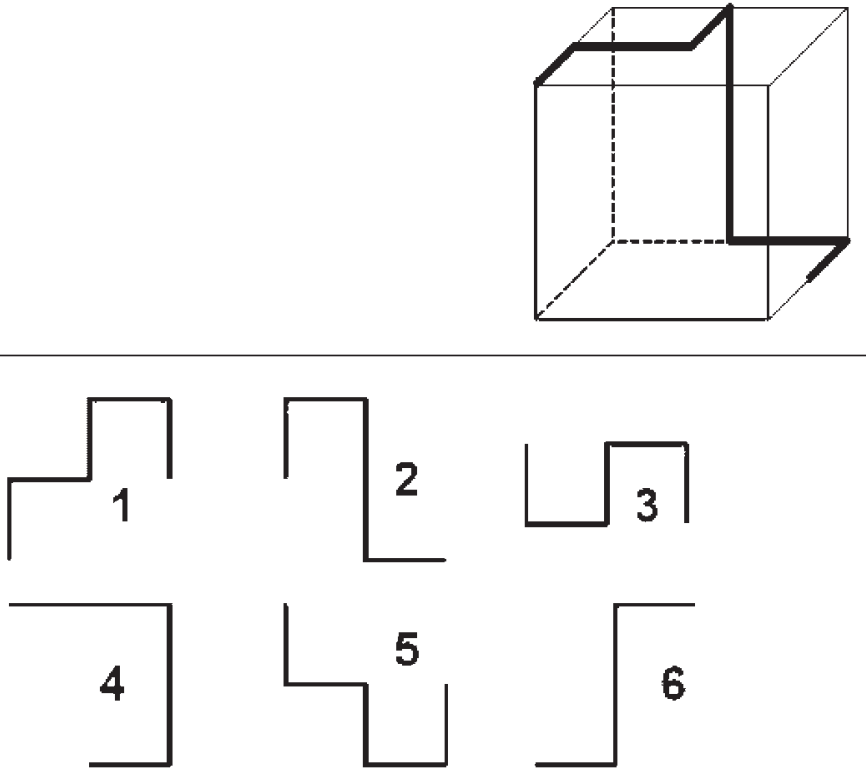

Figure 1. An example of a Wire Frame problem from the Spatial Imagery Test from the Imagery Testing Battery (Version 1.0). The instruction for this example was to imagine looking from beneath the cube and to choose the correct 2-dimensional rendering of the wire from that view. The correct answer in the example is 5
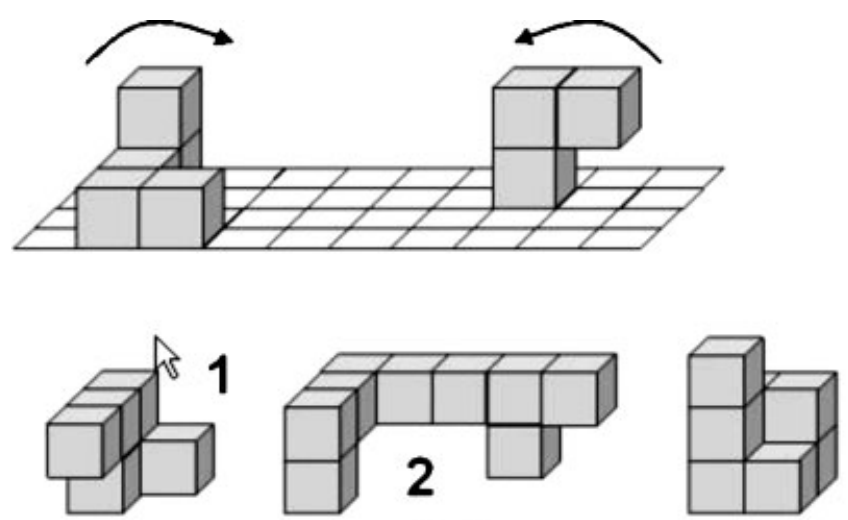

3

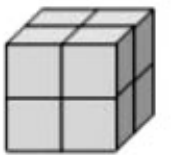

4

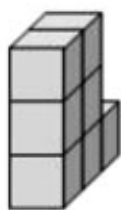

5

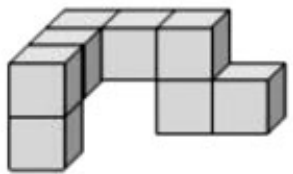

6

Figure 2. An example of a Figure Rotation and Combination problem from the Spatial Imagery Test from the Imagery Testing Battery (Version 1.0). The instruction was to imagine rotating the figure on the left $90^{\circ}$ to the right, to imagine rotating the figure on the right $90^{\circ}$ to the left, and then to select from the six options the one that correctly depicts the combined rotated figures. The correct answer in the example is 6 


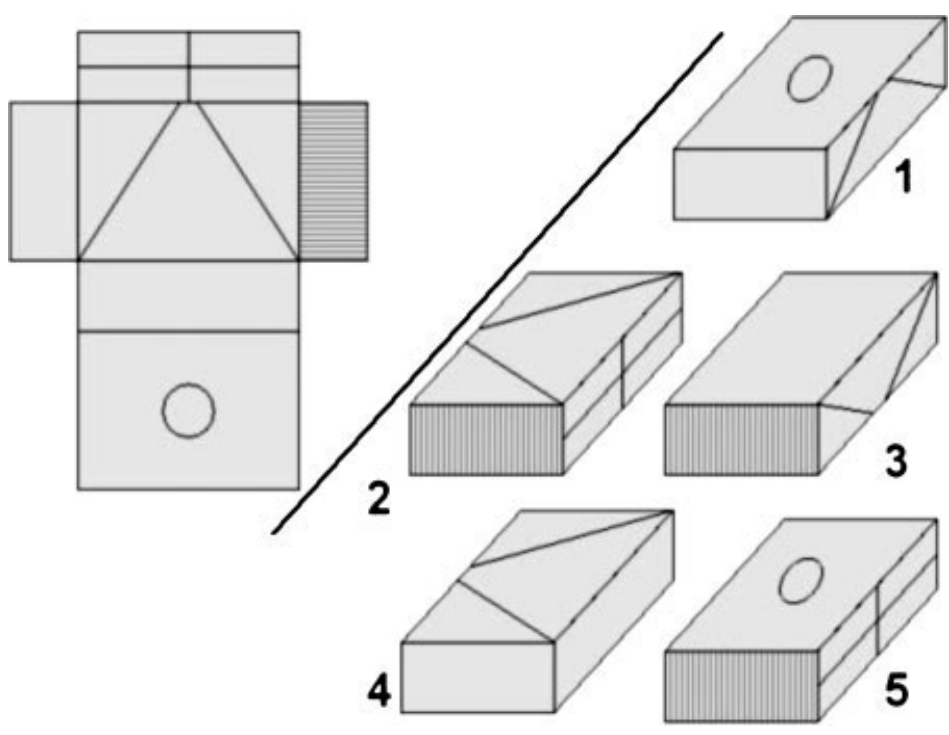

Figure 3 An example of a Folded Box problem from Spatial Imagery Test from the Imagery Testing Battery (Version 1.0). The instruction was to select the box that could be made from the unfolded template. The correct answer in the example is 4

the figure on the left $90^{\circ}$ to the right and by rotating the figure on the right $90^{\circ}$ to the left. Then participants were to indicate which one of six rendered models corresponded to the combined figure. Finally, each Folded Box problem consisted of viewing a rendering of an unfolded template of a rectangular box that had distinct patterns on each of its sides (see Figure 3). Participants were to imagine folding the template into a box and then to determine which one of five models corresponded to the folded template. The Spatial Imagery Test had 30 problems (12 Wire Frame, nine Rotation and Combination and nine Folded Box problems), and for each problem, both reaction time and accuracy were recorded. For the current sample, the Spatial Imagery Test K-R 20 $=0.87$.

Degraded Pictures Test. The Degraded Pictures test was composed of several perceptual closure problems and was designed to measure object imagery. The Degraded Picture Test was considered to require object rather than spatial imagery, because top-down processing has to be used to complete obscured portions of the object, and this top-down completion process should rely on the mechanisms that underlie object imagery (see Kosslyn, 1994). Additionally, imagery vividness ratings have been shown to predict performance on perceptual closure tasks (Wallace, 1990), and furthermore, Kozhevnikov et al. (2005) found that object visualizers were more accurate than spatial visualizers at identifying the objects in degraded pictures. The pencil-and-paper and computerized versions of the Degraded Pictures Test each consisted of the same 20 items. Each item was a degraded line-drawing of a common object (e.g. umbrella, scissors, table, see Figure 4). The degrading was accomplished by deleting segments of bitmapped line-drawings and adding random-noise (patches of black pixels). For both the pencil-and-paper and computerized tests, participants were to identify the objects in the 20 degraded pictures. For the paper-and-pencil version of the test, participants had 4 min to complete the test. For the computerized version of the test, one picture at a time was presented. After identifying the object, the participant used a 


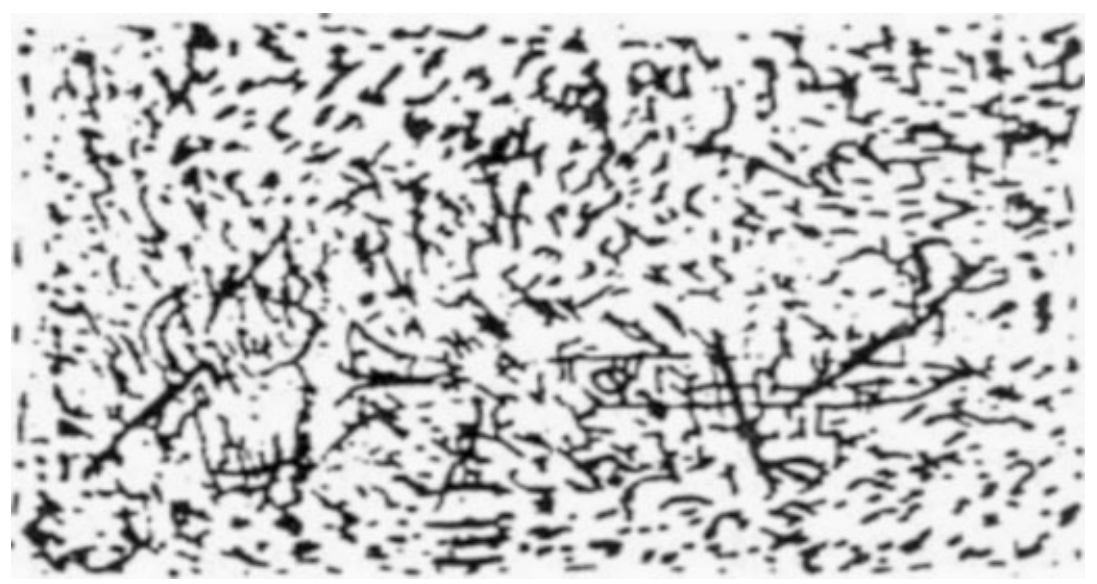

Figure 4. An example of an item from the Degraded Pictures Test from the Imagery Testing Battery (Version 1.0). The instruction was to identify the degraded object. The correct answer in the example is scissors

computer mouse to click a button on the screen to stop the software timer that started when the degraded picture appeared (i.e. to record the reaction time), and then the participant typed the name of the object. The computerized test showed slightly higher internal reliability than the pencil-and-paper test (for the current samples, the pencil-and-paper test K-R $20=0.62$, and for accuracy, the computerized test K-R $20=0.74$.

Vividness of Visual Imagery Questionnaire. The VVIQ (Marks, 1973) is a frequently used self-report measure of the vividness of visual mental images (see McKelvie, 1995). The VVIQ consisted of 16 items in which the participants rated the vividness of mental images they were asked to create (e.g. The sun is rising above the horizon into a hazy sky; and a strong wind blows on the trees and on the lake, causing waves). VVIQ scores were created by summing the 16 ratings, and for the VVIQ, Cronbach's $\alpha \approx 0.88$ (see McKelvie, 1995).

\section{Results}

For both Studies 2a and 2b, participants' OSIQ object and spatial scale scores were created by averaging their ratings on object and spatial items, respectively. The descriptive statistics for the measures used in these studies are presented in Table 2 and Table 3 , respectively. For the computerized tests, RTs for correct responses were analysed, and RTs

Table 2. Descriptive statistics for the measures used in Study 2a

\begin{tabular}{lcccc}
\hline & Mean & SD & Minimum & Maximum \\
\hline OSIQ object scale & 3.55 & 0.56 & 1.80 & 4.67 \\
OSIQ spatial scale & 2.80 & 0.58 & 1.20 & 4.40 \\
Paper Folding & 4.67 & 2.79 & 0.00 & 10.00 \\
Mental rotation & 3.51 & 2.58 & 0.00 & 10.00 \\
Degraded pictures & 6.76 & 2.84 & 0.00 & 13.00 \\
VVIQ & 61.71 & 8.55 & 39.00 & 80.00 \\
\hline
\end{tabular}


Table 3. Descriptive statistics for the measures used in Study 2b

\begin{tabular}{lrrcr}
\hline & Mean & SD & Minimum & Maximum \\
\hline OSIQ object scale & 3.60 & 0.49 & 2.53 & 4.67 \\
OSIQ spatial scale & 2.70 & 0.56 & 1.47 & 4.60 \\
Degraded pictures & 8.40 & 3.60 & 2.00 & 16.00 \\
Degraded pictures RT (sec) & 7.65 & 5.28 & 2.51 & 31.70 \\
Paper Folding & 4.10 & 2.54 & 0.00 & 9.00 \\
Mental rotation & 4.08 & 2.90 & 0.00 & 10.00 \\
Spatial Imagery Test & 7.80 & 5.70 & 0.00 & 23.00 \\
Spatial Imagery Test RT (sec) & 24.65 & 16.67 & 2.37 & 66.53 \\
\hline
\end{tabular}

with $z$-scores that exceeded 2.5, where $z$-scores computed based on the distributions of each participant's responses, were excluded. Overall, five data points from the Spatial Imagery Test and two data points from the Degraded Pictures Test were excluded.

\section{Study $2 a$}

The correlations amongst the OSIQ scales, the Paper Folding Test, the Vandenberg-Kuse Mental Rotation Test, the Degraded Pictures Test, and the VVIQ are presented in Table 4. The OSIQ spatial scale was significantly correlated with the Paper Folding Test and with the Vandenberg-Kuse Mental Rotation Test, and the correlation coefficients, respectively, were within McKelvie's (1994) marginal $(0.10 \leq r \leq 0.24)$ and acceptable $(0.25 \leq r \leq 0.39)$ convergent validity coefficient ranges. Additionally, the OSIQ spatial scale was not correlated with the Degraded Pictures Test, but the OSIQ spatial scale was weakly correlated $(r=0.18, p=0.031)$ with the VVIQ. This latter correlation, however, was not replicated in Study 3 reported below, and the correlation coefficients, respectively, were within McKelvie's inconsequential $(r \leq 0.15)$ and acceptable $(0.16 \leq r \leq 0.25)$ divergent validity ranges. In contrast to the OSIQ spatial scale, the OSIQ object scale was significantly correlated with the Degraded Pictures Test and the VVIQ, and the coefficients, respectively, were within McKelvie's marginal and very good $(r \geq 0.40)$ convergent validity ranges. Finally, the OSIQ object scale was not significantly correlated with either the Paper Folding Test or the Vandenberg-Kuse Mental Rotation Test, and both coefficients were within McKelvie's inconsequential divergent validity range.

Table 4. The Pearson product-moment correlations among the OSIQ spatial and object scores and the measures of spatial and object imagery administered in study $2 \mathrm{a}$

\begin{tabular}{|c|c|c|c|c|c|c|}
\hline & 1 & 2 & 3 & 4 & 5 & 6 \\
\hline $\begin{array}{l}\text { 1. OSIQ object scale } \\
{ }_{*}\end{array}$ & - & 0.085 & -0.104 & 0.107 & $0.190 *$ & $0.484-$ \\
\hline 2. OSIQ spatial scale & & - & $0.217 * *$ & $0.255^{* *}$ & 0.047 & $0.179 *$ \\
\hline 3. Paper Folding & & & - & $0.505^{* *}$ & $0.258 * *$ & 0.078 \\
\hline 4. Mental Rotation & & & & - & $0.169 *$ & 0.144 \\
\hline 5. Degraded Pictures & & & & & - & $0.256^{*}$ \\
\hline 6. VVIQ & & & & & & - \\
\hline
\end{tabular}


Table 5. The Pearson product-moment correlations amongst the OSIQ spatial and object scores and the measures of spatial and object imagery used in study $2 \mathrm{~b}$

\begin{tabular}{lcccccccc}
\hline & 1 & 2 & 3 & 4 & 5 & 6 & 7 & 8 \\
\hline 1. OSIQ object scale & - & -0.245 & $-0.328^{*}$ & -0.189 & -0.242 & -0.124 & $0.312^{*}$ & 0.050 \\
2. OSIQ spatial scale & & - & $0.507^{* *}$ & $0.494^{* *}$ & $0.470^{* *}$ & 0.254 & -0.047 & 0.174 \\
3.Paper Folding & & & - & $0.626^{* *}$ & $0.640^{* *}$ & 0.086 & -0.025 & -0.137 \\
4. Mental Rotation & & & & - & $0.559^{* *}$ & 0.049 & 0.070 & -0.015 \\
5. Spatial Imagery Test & & & & - & $0.338^{*}$ & 0.204 & 0.077 \\
6. Spatial Imagery Test RT & & & & & - & $0.392^{* *}$ & $0.438^{* *}$ \\
7. Degraded Pictures & & & & & & - & & - \\
8. Degraded Pictures RT & & & & & & & - \\
\hline
\end{tabular}

$* p<0.05$.

$* * p<0.01$

\section{Study $2 b$}

The correlations amongst the OSIQ scales, the Paper Folding Test, the Vandenberg-Kuse Mental Rotation Test, the Spatial Imagery Test, and the computerized Degraded Pictures Test are presented in Table 5. The correlations are consistent with those found in Study 2a. The OSIQ spatial scale was significantly correlated with the Paper Folding Test, the Vandenberg-Kuse Mental Rotation Test, and accuracy on the Spatial Imagery Test (but not RT; however, RT was highly variable across participants, see Table 3, and the coefficient was still within McKelvie's, 1994, acceptable convergent validity range), and the correlation coefficients, respectively, were within McKelvie's very good $(r \geq 0.40)$ convergent validity coefficient range. The OSIQ spatial scale was not significantly correlated with either accuracy or RT for the Degraded Pictures Test, and the coefficients, respectively, were within McKelvie's acceptable and inconsequential divergent validity ranges. In contrast, the OSIQ object scale was significantly correlated with accuracy on the Degraded Pictures Test (but not RT; but RT was highly variable across participants, see Table 3), and the coefficient was within McKelvie's acceptable convergent validity range. Finally, the OSIQ object scale was negatively correlated with the Paper Folding Test and also negatively, although non-significantly, correlated with the Vandenberg-Kuse Mental Rotation and Spatial Imagery tests, thus further supporting the divergent validity of the object scale.

Overall, the data from Studies $2 \mathrm{a}$ and $2 \mathrm{~b}$ provided further validation of the OSIQ as a measure of spatial and object imagery preferences and thus provided further support for the hypothesis that imagery is not a unified, undifferentiated construct. The OSIQ spatial scale was positively correlated with measures of spatial imagery and overall not correlated with measures of object imagery, with the exception of a weak correlation with the VVIQ in Study 2a. In contrast, the OSIQ object scale was positively correlated with measures of object imagery, but not correlated or inversely correlated with measures of spatial imagery.

These results have important implications because they provide a clear explanation for previous failures to find significant correlations between imagery self-report questionnaires and spatial imagery tests. We believe, like Reisberg and colleagues (Heuer et al., 1986; Reisberg et al., 1986), that the items on most of the previous imagery questionnaires were targeted to measure aspects of object but not spatial imagery (e.g. items on the VVIQ assessed the colourfulness, brightness, and vividness of the images constructed from long-term memory), yet most of the standard psychometric imagery tests assess aspects of spatial imagery (e.g. the transformations of elements of mental images). 
The pattern of correlations between the OSIQ spatial scale and spatial imagery tasks, however, indicates that it is possible to use subjective ratings of imagery to predict performance on spatial imagery tasks, but the ratings must be of spatial imagery processes (e.g. asking people to rate whether their images are schematic, to rate their ability to manipulate and transform their images spatially, and to rate their ability to perform everyday spatial imagery tasks) and not object imagery processes (e.g. vividness).

\section{STUDY 3}

Previous research has shown that spatial imagery ability is associated with successful performance on a number of analytical tasks (e.g. Hegarty \& Kozhevnikov, 1999). Thus, people with higher intelligence might tend to report themselves as spatial imagers. Therefore, Study 3 was designed to assess the discriminant validity of the OSIQ by ruling out the possibility that differences in OSIQ spatial imagery scores reflect differences in general intelligence rather than spatial imagery preferences. Therefore, in this study, the OSIQ scale scores were correlated with measures of verbal and non-verbal intelligence. Additionally, tests of spatial and object imagery were included to provide further predictive validity of the OSIQ. Thus, the participants were individually administered the OSIQ, a verbal intelligence test, a non-verbal intelligence test, a verbal ability test, a spatial imagery test, and an object imagery test.

\section{Method}

\section{Participants}

Forty-five undergraduate and graduate students (27 females and 18 males), ranging from 18 to 30 years of age, were recruited from the participant pool at Rutgers UniversityNewark and through advertisements posted around the Rutgers and New Jersey Institute of Technology campuses.

\section{Materials}

Participants were administered the OSIQ, the Advanced Progressive Matrices non-verbal intelligence test (APM; Raven, Raven, \& Court, 1998), the Similarities verbal intelligence test from the WAIS-III (Wechsler, 1997), and the Advanced Vocabulary Test (Ekstrom et al., 1976). Additionally, they completed the VVIQ (Marks, 1973) and the Paper Folding Test (Ekstrom et al., 1976).

Advanced Progressive Matrices. The APM (Raven et al., 1998) consisted of a set of 36 items. Each item contained an arrangement of spatial figures that were organized in a certain logical pattern. The participant's task was to find which of eight possible figures best completed the pattern. The test-retest reliability is 0.91 (Raven et al., 1998), and for internal consistency, Cronbach's $\alpha=0.84$ (Bors \& Stokes, 1998).

WAIS-III: Similarities. The Similarities test from the WAIS-III (Wechsler, 1997) consisted of 19 pairs of words. Participants were to describe the conceptual similarity between the two words (e.g. in what way are RED and BLUE alike, where the correct answer indicated that they are both colours). Responses were scored according to the 
WAIS-III instructions, and scores on each item varied according to the degree to which the response described a primary, general property pertinent to both items in the pair. The test-retest reliability is 0.83 , and for internal consistency, the split-half reliability is 0.86 (Kaufman \& Lichtenberger, 1999).

Advanced Vocabulary Test. The Advanced Vocabulary Test consisted of 18 items in which participants were to choose which word among five had the same meaning or nearly the same meaning as a target word. The Advanced Vocabulary Test measures 'availability and flexibility in the use of multiple meanings of words' (Ekstrom et al., 1976). The test-retest reliability of the test is 0.83 (Ekstrom et al., 1976).

\section{Procedure}

All participants were tested individually, and the order of the tests was randomized. The participants were strictly limited to $3 \mathrm{~min}$ for the Paper Folding Test, and $30 \mathrm{~min}$ for the APM. No time limit was specified for any of the other tasks, but the participants were instructed to respond as accurately and quickly as possible.

\section{Results and discussion}

Again, as in the previous studies, the OSIQ object and spatial scale scores were created by averaging participants' ratings on the object and spatial imagery items, respectively. The descriptive statistics for the measures used in Study 3 are presented in Table 6. The correlations among the variables are presented in Table 7. Neither the OSIQ spatial scale nor the OSIQ object scale was significantly correlated with the APM, the similarities test from the WAIS-III, nor the Advanced Vocabulary scores, and all of the coefficients were within or below McKelvie's (1994) acceptable divergent validity range. There were weak,

Table 6. Descriptive statistics for the measures used in Study 3

\begin{tabular}{lrlcc}
\hline & Mean & SD & Minimum & Maximum \\
\hline OSIQ object scale & 3.72 & 0.45 & 2.67 & 4.60 \\
OSIQ spatial scale & 2.87 & 0.66 & 1.69 & 4.25 \\
VVIQ & 63.80 & 9.67 & 40.00 & 79.00 \\
Paper Folding & 4.84 & 2.52 & -1.25 & 10.00 \\
AMP & 20.98 & 5.34 & 5.00 & 32.00 \\
WAIS: Similarities & 37.84 & 4.25 & 23.00 & 47.00 \\
Advanced Vocabulary & 7.76 & 2.13 & 3.00 & 14.00 \\
\hline
\end{tabular}

Table 7. The Pearson product-moment correlations amongst the OSIQ spatial and object scores, the measures of spatial and object imagery, and the tests of verbal and non-verbal intelligence in Study 3

\begin{tabular}{lccccccc}
\hline & 1 & 2 & 3 & 4 & 5 & 6 & \multicolumn{1}{c}{7} \\
\hline 1. OSIQ object scale & - & -0.171 & -0.235 & -0.004 & -0.123 & -0.129 & $0.334^{*}$ \\
2. OSIQ spatial scale & & - & 0.199 & -0.204 & -0.245 & $0.370^{*}$ & -0.021 \\
3. APM & & & - & -0.062 & 0.099 & $0.598^{* *}$ & -0.081 \\
4. WAIS: Similarities & & & & - & $0.349^{*}$ & -0.197 & -0.023 \\
5. Advanced Vocabulary & & & & - & -0.180 & -0.238 \\
6. Paper Folding & & & & & & - & 0.016 \\
7. VVIQ & & & & & & - \\
\hline
\end{tabular}


though non-significant, trends between the APM and the OSIQ scales (spatial imagery scale, $r=0.20, p=0.189$, object imagery scale, $r=-0.24, p=0.120)$, and these trends were consistent with results reported by Kozhevnikov et al. (2005). Kozhevnikov et al. reported that spatial imagers were significantly better than object imagers on AMP items that required a more 'analytical' approach, that is, on items that required identifying the correct spatial relations among the objects. However, Kozhevnikov et al. also reported that both spatial and object imagers performed equally well on 'figural' type APM items, that is, items that required primarily visual-spatial analysis and that were based on perceptual operations such as continuation or superimposition. The authors suggested that the poor performance of object imagers on the APM analytical problems might have occurred because object imagers tend to process visual information globally, which sets limitations on their ability to solve tasks requiring analytical-sequential processing of spatial relations. Finally, the correlations between the OSIQ scales and the VVIQ and Paper Folding Test supported the results from Study 2. The object scale was significantly correlated with VVIQ, but the spatial scale was not. In contrast, OSIQ spatial scale was significantly correlated with Paper Folding Test, but the object scale was not. The respective coefficients fit within McKelvie's acceptable convergent validity range and inconsequential divergent validity range.

Thus, the data from Study 3 provide further validation of the OSIQ object and spatial scales. The scales were not significantly correlated with measures of verbal and non-verbal intelligence, and therefore, these results suggest that OSIQ scales assess constructs that are different from general intelligence. The data from Study 3 also confirmed the predictive validity findings from Study 2 in that the OSIQ spatial scale was correlated with the Paper Folding Test but not with the VVIQ and in that the OSIQ object scale was correlated with the VVIQ but not with the Paper Folding Test.

\section{STUDY 4}

The goal of Study 4 was to further examine the criterion (in this study ecological) validity of the OSIQ by administering it to members of different professions. Previous investigators have shown relationships between imagery abilities and areas of specialization (Casey, Winner, Brabeck, \& Sullivan, 1990; Isaac \& Marks, 1994). For example, Isaac \& Marks (1994) found that physical education majors gave higher motor imagery vividness ratings than the groups from the other academic disciplines (physics, English, or surveying). Thus, to examine the ecological validity of the OSIQ, the current study focused on comparing object and spatial imagery ratings among members of different professions whose everyday work involves the extensive use of object imagery or spatial imagery (i.e. visual artists and natural scientists) and a group whose work does not involve the extensive use of imagery (i.e. humanities professionals).

Studies have suggested that visual artists use object imagery extensively in their work. For example, Patrick (1937) and Roe (1975) interviewed visual artists about their creative processes and concluded that imagery experiences are a crucial part of such processes. Furthermore, Rosenberg (1987) provided a qualitative analysis of imagery-related processes during different stages of artistic processes and concluded that visual artists extensively use imagery for collecting and storing images when drawing and evaluating completed paintings. Additionally, Lindauer (1983) interviewed visual artists about the frequency, clarity, vividness, variability, control and other aspects 
of their imagery, and Lindauer found that visual artists characterized their visual images as vivid and clear. Thus, these data show that the imagery used by visual artists has characteristics of object rather than spatial imagery. In fact, major aspects of visual arts training include depicting real objects and scenes, sketching overall shapes and copying other artist's paintings.

Natural science professions, on the other hand, require training in understanding and manipulating abstract representations such as graphs, diagrams and schematic drawings of structures, events and concepts as well as representations of structural relations. Many scientific concepts require the spatial visualization and transformation of schematic 3-dimensional images. For example, the comprehension of 3-dimensional molecular structures, solving abstract 3-dimensional geometrical problems, sketching isometric and orthographic drawings of 3-dimensional objects, and mechanical reasoning problems, all require spatial imagery involving imagining parts and configurations of schematic spatial images and rotating, deconstructing and combining such parts and configurations (e.g. Ferguson, 1977; Hegarty \& Kozhevnikov, 1999; Kozhevnikov et al., 2002; Pellegrino, Mumaw, \& Shute, 1985).

In contrast, humanities professionals involved in fields such as language arts, history, or philosophy work predominantly with verbal materials, and their major training requires the extensive reading, comprehension, analysis, production, and discussion of verbal materials. According to the distinction drawn in the cognitive style literature between visualizers and verbalizers (Pavio, 1971; Richardson, 1977; Riding \& Cheema, 1991), such humanities professions should primarily consist of verbalizers (i.e. those who predominantly prefer to represent and process information verbally), as opposed to visualizers (i.e. those who predominantly prefer to represent and process information visually).

In the current study, visual arts, science and humanities professionals were administered the OSIQ. Members of these professional groups were expected to differ in their scores on the OSIQ spatial and object scales. In particular, visual arts professionals were expected to score highest on the OSIQ object imagery scale, and science professionals were expected to score highest on the OSIQ spatial imagery scale.

\section{Method}

\section{Participants}

The participants were 75 professionals who held college degrees and had at least two years working experience in their respective professions. The group of visual artists consisted of 28 professionals ( 17 females): 18 designers and 10 visual artists. All of the visual arts professionals received formal educations in classical visual arts, including training in painting, colours, and drawing shapes and forms. The group of scientists consisted of 24 professionals ( 5 females): nine computer scientists, four physicists, four biologists, three engineers, two biochemists, one chemist and one mathematician. Finally, the group of humanities professionals consisted of 23 professionals (14 females): 11 historians, five philosophers, four English professors, two literature professors, and one journalist.

\section{Procedure}

All of the participants were individually administered the OSIQ as a part of a battery of visual/spatial tests, that took approximately one hour to complete. The additional tests included in the battery were a part of another study to be reported elsewhere. 


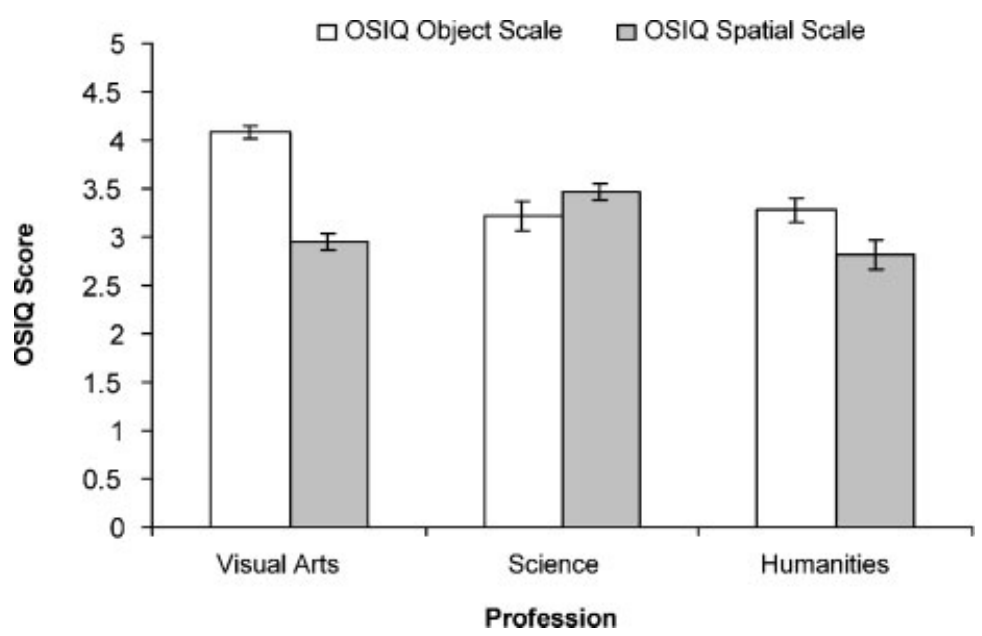

Figure 5. Mean scores for the OSIQ imagery scales for the different groups of professionals. The bars represents $\pm 1 \mathrm{SEM}$

\section{Results and discussion}

A one-way ANOVA revealed a significant difference in OSIQ object scale scores between the professional groups, $F(2,72)=19.92, p<0.001$ (see Figure 5). Tukey's HSD revealed that the visual artists' OSIQ object scores were significantly higher than the scientists' scores $(p<0.001)$ and than the humanities professionals' scores $(p<0.001)$; however, OSIQ object scores did not significantly differ between the scientists and humanities professionals. A one-way ANOVA also revealed a significant difference in OSIQ spatial scale scores between the professional groups, $F(2,72)=9.59, p<0.001$. Tukey's HSD revealed that the scientists' OSIQ spatial scores were significantly higher than the visual artists' scores $(p=0.003)$ and than the humanities professionals' scores $(p<0.001)$; however, the OSIQ spatial scores did not significantly differ between visual artists and humanities professionals (see Figure 5).

Thus, as predicted, the results showed that scientists scored higher than visual artists and humanities professionals on the spatial imagery scale, whereas visual artists scored higher than scientists and humanities professionals on objects imagery scale. Thus, these findings further confirm the validity of the OSIQ as an instrument assessing object and spatial imagery by showing that professionals known to use either object or spatial imagery in their training and work score differently on the scales designed to assess experiences with and preferences for using those types of imagery. Furthermore, the results suggest that visual artists tend to prefer to use object rather than spatial imagery and that scientists tend to prefer to use spatial rather than object imagery, and this finding is consistent with other studies of scientists and visual artists. Casey et al. (1990), for example, demonstrated that engineers, physicists, and mathematicians scored higher on spatial ability tests, whereas visual artists scored higher on visual memory tests. Similarly, Kozhevnikov et al. (2005) found that professional visual artists scored higher on object imagery tests but that professional scientists and engineers scored higher on spatial imagery tests. 


\section{GENDER DIFFERENCES}

Although the examination of gender differences was not the primary goal of the present studies, gender differences in spatial ability (see Linn \& Petersen, 1985; Voyer, Voyer, \& Bryden, 1995) and imagery vividness ratings (see Richardson, 1995; but see McKelvie, 1995) have been reported in the literature, with males typically performing better on mental rotation, spatial perception, and spatial relations tasks and females typically giving higher vividness ratings. Consistent with these reports, males had significantly higher OSIQ spatial imagery scores than females (Study $1 F(1,213)=79.80, p<0.001$, $M$ males $=3.24, S D=0.51, M$ females $=2.62, S D=0.51$; Study $2 \mathrm{a} F(1,145)=12.91$, $p<0.001, M$ males $=2.98, \quad S D=0.52, M$ females $=2.65, \quad S D=0.58 ;$ Study $2 \mathrm{~b}$ $F(1,47)=8.12, p=0.006, M$ males $=2.96, S D=0.58, M$ females $=2.53, S D=0.48$; Study $3 F(1,43)=17.90 ; p<0.001, M$ males $=3.31, S D=0.58, M$ females $=2.58$, $S D=0.55$; and Study $4 F(1,72)=7.083 ; p=0.010, M$ males $=3.24, S D=0.50$, $M$ females $=2.88, S D=0.65$ ). The findings for the OSIQ object imagery scores, however, were mixed. Females had higher OSIQ object imagery than males in Studies 1 and 4 (Study $1 F(1,213)=8.02 ; p=0.005, M$ females $=3.49, S D=0.53, M$ males $=2.70$, $S D=0.60$; and Study $4 F(1,72)=7.76, p=0.007, M$ females $=3.79, S D=0.58$, $M$ males $=3.36, S D=0.73$ ) but not in Studies 2a, 2b, and 3 (Study $2 \mathrm{a} F(1,145)=1.87$, $p=0.173, \quad M$ females $=3.60, \quad S D=0.49, \quad M$ males $=3.48, \quad S D=0.64 ; \quad$ Study $2 b$ $F(1,47)=0.149 ; p=0.701, M$ females $=3.62, S D=0.52, M$ males $=3.57, S D=0.45$; and Study $3 F(1,43)=2.829, p=0.100, M$ females $=3.82, S D=0.42, M$ males $=3.59$, $S D=0.50)$. Although these gender differences were found, a substantial number of females showed above average spatial imagery preferences (e.g. 29.2\% in Study 1), and a substantial number of males showed above average object imagery preferences (e.g. $42.6 \%$ in Study 1). The two scales, therefore, clearly assess more than gender differences in imagery preferences and experiences.

\section{GENERAL DISCUSSION}

Across the series of studies, the new OSIQ self-report instrument, measuring individuals' experiences in and preferences for spatial and object imagery, was designed and validated. The findings of this research show that a valid self-report instrument can be developed and used for measuring imagery preferences and experiences, if the instrument takes into account the existence of two relatively independent object and spatial imagery systems. Thus, the current research challenges previous attempts to develop valid self-report assessments of imagery experiences where imagery was treated as an undifferentiated construct. In contrast, the OSIQ was designed with items to separately assess object and spatial imagery experiences, and this inclusion of separate object and spatial imagery items helped to avoid the major validity problems found with previous imagery self-report instruments.

The results from Study 1 supported the construct validity of the new instrument. Principal components analysis performed on the OSIQ items revealed a clear factor structure with all of the object imagery items loading on one main factor and all of the spatial imagery items loading on a second main factor. Additionally, the two OSIQ subscales demonstrated acceptable internal reliability (below McKelvie's, 1994, criterion of 0.85, but above Robinson, Shaver, Wrightsman's, 1991, moderate criterion of 0.59). 
The clear factor structure and internal reliability of the OSIQ further supports the value of separately measuring these two aspects of mental imagery. Moreover, the negative correlation between the two OSIQ scales suggests that some people have preferences for using either object or spatial imagery, but not both types of imagery, and this correlation is consistent with other findings showing that object imagers tend to process visual information differently than spatial imagers. Kozhevnikov et al. (2005), for example, suggested that object imagers tend to process visual information globally and holistically but that spatial imagers tend to encode and process visual images analytically and sequentially, part-by-part. In fact, Kosslyn and Anderson (in Kosslyn, 1994, chap. 9) demonstrated that object imagery is based on representations of individual holistic perceptual units but that spatial imagery is based on schematic spatial representations that are arranged sequentially.

All of these findings are important for further understanding the qualitative differences between the two types of imagery and the way that different types of imagers approach and solve different imagery tasks. Indeed, the further investigation of visual processing differences between object and spatial imagers is an interesting direction for future studies. Examining the differences between object and spatial imagers on dimensions such as pictorial versus schematic, holistic versus analytic, and dynamic versus static visual information processing will help to further determine the critical differences between these imagers, and the results of such investigations could be included in self-report questionnaires to aid in better differentiating between object and spatial imagers.

The results from Studies 2a, 2b, and 3 illustrate the convergent and divergent validity of the OSIQ. The data showed that participants' ratings of their imagery experiences and preferences on the object scale correlated significantly with performance on object, but not spatial, imagery tasks. In contrast, participants' ratings of their imagery experiences and preferences on the spatial scale correlated significantly with performance on spatial, but not object, imagery tasks. Thus, these data further demonstrate that the OSIQ scales appear to reliably assess two different types of imagery, and the data further confirm that imagery self-report instruments can be used to successfully predict individuals' performances on objective imagery tests. Therefore, these data suggest that a crucial problem with the criterion validity of previous imagery self-report instruments (i.e. their failure to predict performance on spatial imagery tests) was that these instruments required participants to imagine objects, people and scenes recalled from long-term memory when such imagining requires object rather than spatial imagery processes. Furthermore, the results from Study 3 suggest that the OSIQ object and spatial scales assess differences between object and spatial imagery but not differences in levels of intelligence, thereby providing a test of discriminate validity.

The results from the sample of professionals in Study 4 then provide ecological validation of the OSIQ. In Study 4, visual artists, a group known to use object imagery in their training and work, had higher OSIQ object imagery scores than scientists and humanities professionals, whereas scientists, a group known to use spatial imagery in their training and work, had higher OSIQ spatial imagery scores than visual artists and humanities professionals. The question remains, however, whether professional preferences in object versus spatial imagery are a result of expertise or whether they reflect inborn abilities. Therefore, an interesting direction for future research is to investigate how professional preferences develop in relation to the development of mental imagery abilities. 
The results from Study 4 also suggest that the OSIQ would be a useful instrument in applied settings. For instance, the OSIQ should be a useful instrument for providing vocational guidance and for educational purposes. Object imagery seems to be beneficial for successful performance in creative production (Kunzendorf, 1982) and visual arts tasks (Rosenberg, 1987); whereas, spatial imagery seems to be beneficial for mechanical engineering tasks, technical drawing, mathematics, and physics (Kozhevnikov et al., 2002; Pellegrino et al., 1985). Therefore, the OSIQ should be helpful when considering professional interests. Additionally, the OSIQ should be useful to educators, because knowledge about individual imagery preferences should be useful for developing efficiently targeted teaching methods and materials. The OSIQ, however, was developed and validated using samples of college students and adult professionals. Therefore the complexity and content of some of the items might be inappropriate for certain populations (e.g. children), and future studies should examine developmental and crosscultural issues.

Overall, the OSIQ seems to be a very promising and valuable tool for psychological research and for work in applied settings. As a research tool, the OSIQ should be useful for studying object and spatial imagery and especially for selecting individuals with high imagery skills of each type. In applied settings, understanding particular combinations of imagery skills that underlie successful performance in different professional domains should lead to efficiently conceptualized teaching and training methods for improving performance related to visual-spatial learning, and by assessing both object and spatial imagery preferences, the OSIQ should be useful tool for such work.

\section{ACKNOWLEDGEMENTS}

This research was supported by the National Science Foundation under contracts REC-0106760 and REC 135918 to Maria Kozhevnikov.

\section{REFERENCES}

Alesandrini, K. L. (1981). Pictorial-verbal and analytical-holistic learning strategies in science learning. Journal of Educational Psychology, 73, 358-368.

Bors, D. A., \& Stokes, T. L. (1998). Raven's advanced progressive matrices: norms for first-year university students and the development of a short form. Educational and Psychological Measurement, 58, 382-398.

Boswell, D. L., \& Pickett, J. A. (1991). A study of the internal consistency and factor structure of the Verbalizer-Visualizer Questionnaire. Journal of Mental Imagery, 15, 33-36.

Casey, M., Winner, E., Brabeck, M., \& Sullivan, K. (1990). Visual-spatial abilities in art, maths, and science majors: effects of sex, handedness, and spatial experience. In K. Gilhooly, M. Keane, R. Logie, \& G. Erdos (Eds.), Lines of thinking: Reflections on the psychology of thought: Skills, emotion, creative processes, individual differences and teaching thinking (Vol. 2, pp. 275-249). New York: Wiley.

Dean, G., \& Morris P. (2003). The relationship between self-reports of imagery and spatial ability. British Journal of Psychology, 94, 245-273.

Edwards, J. E., \& Wilkins, W. (1981). Verbalizer-visualizer questionnaire: relationship with imagery and verbal-visual ability. Journal of Mental Imagery, 5, 137-142.

Ekstrom, R. B., French, J. W., \& Harman, H. H. (1976). Kit of factor-referenced cognitive tests. Princeton, NJ: Educational Testing Service. 
Farah, M. J., Hammond, K. M., Levine, D. N., \& Calvanio, R. (1988). Visual and spatial mental imagery: dissociable systems of representations. Cognitive Psychology, 20, 439-462.

Ferguson, E. S. (1977). The Mind's Eye: nonverbal Thought in Technology. Science, 197, 827-836.

Green, K. E., \& Schroeder, D. H. (1990). Psychometric quality of the Verbalizer-Visualiser Questionnaire as a measure of cognitive style. Psychological Reports, 66, 939-945.

Guadagnoli, E., \& Velicer, W. F. (1988). Relation of sample size to the stability of component patterns. Psychological Bulletin, 103, 265-275.

Hegarty, M., \& Kozhevnikov, M. (1999). Types of visual-spatial representations and mathematical problem solving. Journal of Educational Psychology, 91, 684-689.

Heuer, F., Fischman, D., Reisberg, D. (1986). Why does vivid imagery hurt colour memory? Canadian Journal of Psychology, 40, 161-175.

Hollenberg, C. K. (1970). Functions of visual imagery in the learning and concept formation of children. Child Development, 41, 1003-1015.

Imagery Testing Battery (Version 1.0) [Computer Software]. Newark, NJ: MM Virtual Design, LLC: www.mmvirtualdesign.com

Isaac, A. R., \& Marks, D. F. (1994). Individual differences in mental imagery experience: developmental changes and specialization. British Journal of Psychology, 85, 479-500.

Kaufman, A. S., \& Lichtenberger, E. O. (1999). Essentials of WAIS-III assessment. NY: Jon Wiley \& Sons, Inc.

Kirby, J. R., Moore, P. J., \& Schofield, N. J. (1988). Verbal and visual learning styles. Contemporary Educational Psychology, 13, 169-184.

Kosslyn, S. M. (1994). Image and brain: The resolution of the imagery debate. Cambridge, MA: MIT Press.

Kosslyn, S. M., Ganis, G., \& Thompson, W. L. (2001). Neural foundations of imagery. Nature Reviews Neuroscience, 2, 635-642.

Kosslyn, S. M., \& Koenig, O. (1992). Wet mind: The new cognitive neuroscience. New York: Free Press.

Kozhevnikov, M., Hegarty, M., \& Mayer, R. E. (2002). Revising the visualizer/verbalizer dimension: evidence for two types of visualizers. Cognition \& instruction, 20, 47-77.

Kozhevnikov, M., \& Kosslyn, S. M. (2000, November). Two orthogonal classes of visualizers. Paper presented at the 41st annual meeting of the Psychonomic Society, New Orleans, LA.

Kozhevnikov, M., Kosslyn, S. M., \& Shepard, J. (2005). Spatial versus object visualizers: a new characterization of visual cognitive style. Memory and Cognition, 33, 710-726.

Kunzendorf, R. (1982). Mental images, appreciation of grammatical patterns, and creativity. Journal of Mental Imagery, 6, 183-202.

Lean, C., \& Clements, M. A. (1981). Spatial ability, visual imagery, and mathematical performance. Educational Studies in Mathematics, 12, 267-299.

Levine, D. N., Warach, J., \& Farah, M. J. (1985). Two visual systems in mental imagery: dissociation of 'what' and 'where' in imagery disorders due to bilateral posterior cerebral lesions. Neurology, $35,1010-1018$.

Lindauer, M. S. (1983). Imagery and the arts. In A. A. Sheihk (Ed.), Imagery: Current Theory, Research, and Application. New York: Wiley.

Linn, M. C., \& Petersen, A. C. (1985). Emergence and characterization of sex differences in spatial abilities: a meta-analysis. Child Development, 56, 1479-1498.

Lohman, D. (1979). Spatial ability: A review and reanalysis of the correlational literature (Tech. Rep. No. 8). California, Stanford University, Aptitude Research Project, School of Education.

Marks, D. F. (1973). Visual imagery differences in the recall of pictures. British Journal of Psychology, 64, 17-24.

Marks, D. F. (1983). In defense of imagery questionnaires. Scandinavian Journal of Psychology, 24, 243-246.

McKelvie, S. J. (1994). Guidelines for judging the psychometric properties of imagery questionnaires as research instruments: a quantitative proposal. Perceptual and Motor Skills, 79, 1219-123.

McKelvie, S. J. (1995). The VVIQ as a psychometric test of individual differences in visual imagery vividness: a critical quantitative review and plea for direction. Journal of Mental Imagery, 19, $1-106$.

Milner, A. D., \& Goodale, M. A. (1995). The visual brain in action. Oxford: Oxford University Press. Paivio, A. (1971). Imagery and verbal processes. Oxford: Holt, Rinehart \& Winston. 
Paivio, A. (1983). The empirical case for dual coding. In J.C. Yuille (Ed.), Imagery, memory and cognition. Hillsdale, NJ: Lawrence Erlbaum Associates.

Paivio, A., \& Harshman, R. (1983). Factor analysis of a questionnaire on imagery and verbal habits and skills. Canadian Journal of Psychology, 37, 461-483.

Parrot, C. A. (1986). Validation report on the Verbalizer-Visualizer Questionnaire. Journal of mental imagery, 10, 38-42.

Patrick, C. (1937). Creative thought in artists. Journal of Psychology, 4, 35-73.

Pellegrino, J. W., Mumaw, R. J., \& Shute, V. J. (1985). Analyses of spatial aptitude and expertise. In S. Embretson (Ed.), Test design: Contributions from psychology, education and psychometrics (pp. 45-76). New York: Academic Press.

Poltrock, S. E., \& Agnoli, F. (1986). Are spatial visualization ability and visual imagery ability equivalent? In R. J. Sternberg (Ed.), Advances in the psychology of human intelligence (Vol. 3, pp. 255-296). Hillsdale, NJ: Lawrence Erlbaum.

Presmeg, N. C. (1986a). Visualization and mathematical giftedness. Educational Studies in Mathematics, 17, 297-311.

Presmeg, N. C. (1986b). Visualization in high school mathematics. For Learning of Mathematics, 63, 42-46.

Raven, J., Raven, J. C., \& Court, J. H. (1998). Manual for Raven's advanced progressive matrices. Oxford: Oxford Psychologists Press.

Reisberg, D., Culver, Heuer, L. C., \& Fischman, D. (1986). Visual memory: when imagery vividness makes a difference. Journal of Mental Imagery, 10, 51-57.

Richardson, A. (1977). Verbalizer-visualizer: a cognitive style dimension. Journal of Mental Imagery, 1, 109-125.

Richardson, J. T. E. (1980). Mental imagery and human memory. NY: St. Martin's Press, Inc.

Richardson, J. T. E. (1995). Gender differences in the vividness of visual imagery questionnaire: a meta-analysis. Journal of mental imagery, 19, 177-187.

Riding, R., \& Cheema, I. (1991). Cognitive styles: an overview and integration. Educational Psychology, 11, 193-215.

Robinson, J. P., Shaver, P. R., \& Wrightsman, L. S. (Eds.). (1991). Measures of personality and social psychological attitudes. San Diego, CA: Academic Press.

Roe, A. (1975). Painters and painting. In I. A. Taylor, \& J. W. Getzels (Eds.), Perspectives in creativity. Chicago: Aldine.

Rosenberg, H. S. (1987). Visual artists and imagery. Imagination, Cognition, and Personality, 7, 77-93.

Shepard, R. N., \& Metzler, J. (1971). Mental rotation of three-dimensional objects. Science, 171, 701-703.

Stevens, J. (1996). Applied multivariate statistics for the social sciences (3rd ed.). Mahwah, NJ: Lawrence Erlbaum Associates.

Uhl, F., Goldenberg, G., Lang, W., \& Lindinger, G. (1990). Cerebral correlates of imagining colours, faces and a map-II: negative cortical DC potentials. Neuropsychologia, 28, 81-93.

Vandenberg, S. G., \& Kuse, A. R. (1978). Mental Rotations, a group test of three-dimensional spatial visualization. Perceptual \& Motor Skills, 47, 599-604.

Voyer, D., Voyer, S., \& Bryden, M. P. (1995). Magnitude of sex differences in spatial abilities: a meta-analysis and consideration of critical variables. Psychological Bulletin, 117, 250-270.

Wallace, B. (1990). Imagery vividness, hypnotic susceptibility, and the perception of fragmented stimuli. Journal of Personality and Social Psychology, 58, 354-359.

Wechsler, D. (1997). Wechsler adult intelligence scale (3rd ed.). San Antonio, TX: The Psychological Corporation.

Wilson, J. R., DeFries, J. C., McClean, G. E., Vandenberg, S. G., Johnson, R. C., \& Rashad, M. N. (1975). Cognitive abilities: use of family data as a control to assess sex and age differences in two ethnic groups. International Journal of aging and Human Development, 6, 261-276. 


\section{APPENDIX}

Examples of items from the Paper Folding Test (Ekstrom et al., 1976).

In this test, you are to imagine the folding and unfolding of pieces of paper. In each row, the figures on the left represent a square piece of paper being folded, and the last of these figures has one or two small circles drawn on it to show where the paper has been punched after being folded. One of the five figures on the right correctly shows where the holes will be when the paper is unfolded. You are to decide which one of these figures is correct.
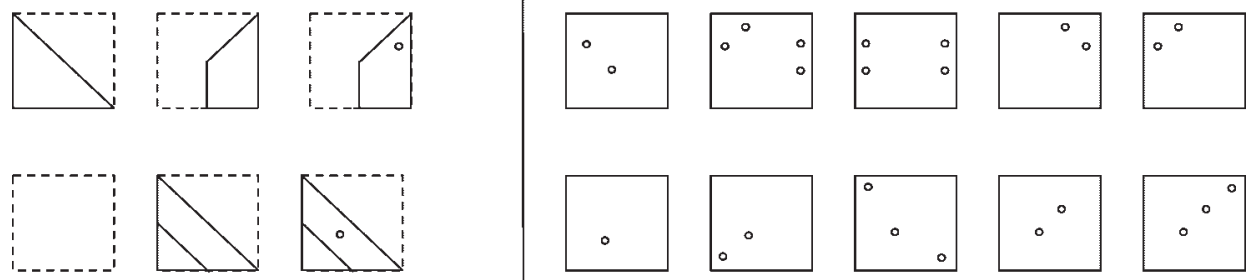

An example of the item from Mental Rotation Test (Vandenberg \& Kuse, 1978).

For each problem there is a primary object on the far left. You are to determine which two of the four objects on the right are the same as the object on left.
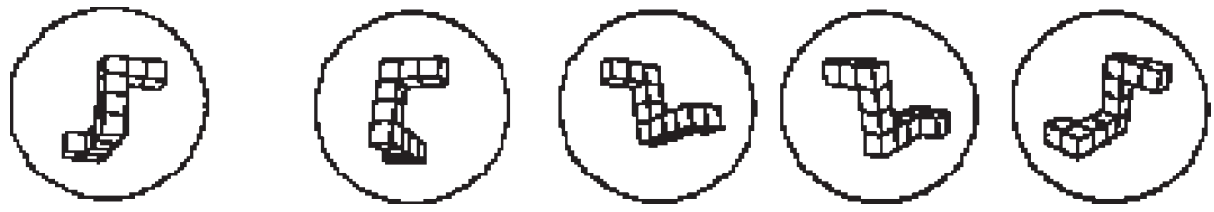